EUROPEAN COMMISSION

DIRECTORATE GENERAL FOR RESEARCH

Unit K-2 Science and Technology Foresight

FORESIGHT WORKING PAPERS SERIES

SERIE DOCUMENTS DE TRAVAIL PROSPECTIFS

$\mathbf{N}^{\circ} \mathbf{1}$

\title{
The objective of Sustainable Development: are we coming closer?
}

\author{
by René von Schomberg*
}

A layman asking an expert: I heard the sun will cease to shine in about 5 billion years?

Answer of the expert: Well, in fact, according to the last estimates, our sun will last about 10 billion years.

Layman's response: Thanks goodness!

\footnotetext{
${ }^{*}$ Scientific Officer at the European Commission. This working paper is written for the publication series Foresight Working Papers, an activity of the science and technology foresight unit of DG Research. The views expressed here are those of the author and may not in any circumstances be regarded as stating an official position of the European Commission. The author expresses his gratitude for comments received on earlier drafts of this paper from Arie Rip, Carl Mitcham, Jerry Ravetz, Silvio Funtowicz, Poul Harremoes and colleagues from the European Commission. This working paper can be downloaded from the website:

http://www.cordis.lu/foresight/working.htm
} 


\section{History and context of the concept}

Although the concept of "sustainability" has a longer history, it was not earlier than in the 1987 report of the World Commission on Environment and Development entitled "Our common future", commonly referred to as the Brundtland report, in which for the first time the concept of "sustainable development" was introduced in order to establish the linkage between economic development and major environmental problems. In order to tackle economic development and environment interdepencies, the Brundtland report called for political and economic change both at the local and at the global level. The Brundtland report defines sustainable development as a development that "meets the needs of the present without compromising the ability of future generations to meet their own needs". It contains within it two key concepts:

- The concept of needs, in particular the essential needs of the world's poor, to which over-riding priority should be given;

- The idea of limitations imposed by the state of technology and social organisations on the environment's ability to meet present and future needs.

These two key concepts were related to a diagnosis of the world situation at the time which, among others, made clear that:

- In the South, population growth is outstripping economic growth (a trend which could not be observed earlier than in the beginning of the eighties).

- Economic growth has become increasingly inequitable, not in the least because of a growing resources gap between industrial nations and the developing world.

The role of technology was not fully incorporated in the diagnosis for addressing sustainable development but it can be argued that the following view on technological progress was not uncommon at the time:

- The role of technological progress can be described as a double agent. On the one hand, technologies can induce a more intensive exploitation of resources but on the other hand technological progress can contribute to more efficient use of resources and provide alternative solutions

The popularity of the Brundtland report can, among others, be explained by a sociopolitical shift in the North in the second half of the eighties: The rich countries were starting to take an active interest in the environmental problems in the poor countries (destruction of tropical rainforests etc) and some other environmental problems could now clearly be observed to affect the whole world (ozone depletion and greenhouse effect). Furthermore, the Brundtland report was based on the premise of economic growth, which made it acceptable for both developing and developed countries.

The concern about environment, inequity and development was echoed at the UNCED conference in Rio de Janeiro (1992). The outcome of the conference, the Rio Declaration, encompasses 27 principles of which principle 25 reads: "Peace, development and environmental protection are interdependent and cannot be seen in isolation of each other". The principle of sustainable development was also formally 
adopted and Agenda 21, a comprehensive plan of action for the 21st century was signed by well over 150 countries. Although the interdependence of economy and ecology was now formally acknowledged by a global community, the north and south continued to emphasise their own preoccupations: the North put their money on the negotiations of major environmental treaties whereas the South emphasised the North's responsibility for the world's environmental problems and demanded resources (also in technological terms) for the eradication of underdevelopment.

The concept of Sustainable Development has crystallised down to entail three pillars: economic development, social development and environmental protection (Copenhagen, Social Summit of 1995, and at the EU level: the Amsterdam Treaty of 1997).

In the run up to the World Summit on Sustainable Development (WSSD) (2002) the fundamental challenges in trying to find a way to embark on a route of sustainable development remain as they were before Rio 1992. In fact, today's "background data" seem to look worse than the already disturbing ones which provided the basis of the Brundlandt report. UN 1991 predictions showed the number of a 7.7 billion global population by 2060 whereas current estimates now claim a 9 billion peak by 2050 (albeit that this number was downwards corrected since 1994, among others by the ever increasing impact of the AIDS epidemic (life expectancy has decreased in 33 countries)). Recently a decline in the birth rate world wide has been identified.

The 1999 Human Development Report published for the United Nations Development Programme (UNDP) delivers a critical assessment of the process of globalisation, a process which is understood to entail the emergence of new markets, new actors - the World Trade Organisation (WTO) with authority over national states, multinational corporations with more economic power than many states, a growing network of nongovernmental organisations (NGOs) and new rules (multilateral agreements on trade, intellectual property and environment which reduce the scope for national policy). The UNDP report states that the era of globalisation opens the opportunity to eradicate poverty in the 21 st century by, among other things, increased trade and new technologies. At the same time, it also states that today's globalisation is primarily driven by market expansion "outpacing governance of these markets and their repercussions for people" (UNDP 1999, page $2 \mathrm{ff}$ ). The adverse consequence of globalisation is that the benefits and opportunities of this process are not widely shared. In fact, 80 countries now have per capita incomes lower than a decade or more ago. Inequality within and between countries has drastically increased. The UNDP report makes it clear that income, resources and wealth have increasingly been concentrated in a few OECD countries (UNDP 1999, page $2 \mathrm{ff}$ ). The recent wave of mergers and acquisitions has concentrated industrial power at the risk of eroding competition. For instance, by 1998 the top ten companies in pesticides controlled 85 percent of a US \$ 31 billion global market (ibid.: 3). On the sharing of key new technologies the situation is even more dramatic: in the area of agricultural biotechnology, for example, only 5 multinationals operate on the US and European market.

In comparison with the background situation of the Brundlandt report, one can not otherwise conclude that the threefold negative tendencies of a population growth, not being compensated by necessary parallel economic developments, a widening 
resources gap (together with an increase of pressures on the environment and natural resources) and a continued increase of inequity have been augmented.

In sum, the diagnosis of today turns out to be worse than in 1987, and in addition to the resources gap, a new gap is increasingly becoming more relevant for the sustainability diagnosis of the situation of the world: a technological gap. The double agent of technology is now showing a new negative characteristic: the benefits of especially new technologies, e.g. information technology and biotechnology is not equally shared.

\section{The International policy agenda on Sustainable Development from Rio 1992 to Johannesburg 2002}

The Commission on Sustainable Development (CSD) was set up shortly after the Rio Conference and consists out of 53 members elected according to a regional attribution key. The CSD is charged to supervise the implementation of Agenda 21 on the local, regional and international level, to work out guidelines and political options for a Rio follow up and to contribute to a dialogue between the UN, civil society and governments. The hope that this institution could devote itself with some authority to all kinds of cross-cutting issues concerning global environmental and development policies has diminished over time, partly because the most important decisions are still taken at the sectorial level and partly due to the fact that the CSD conferences are attended by Ministers for Development/Environment and not by Ministers for Finance/Trade/Commerce. Some of the international negotiation processes which the CSD has launched have been clearly disappointing, notably the lack of agreement on any legal instrument concerning Forests and the current UN forum on Forests can not otherwise than focus on trying to help solve problems at the regional or local level, thereby depending on national governments who themselves, by large, have insufficient means to turn things to the better.

At the nineteenth Special Session of the UN General Assembly (RIO plus 5) in 1997, governments have reviewed progress in implementing the Rio commitments. Developing countries are dissatisfied by the lack of commitment from donor countries to increase the level of official development assistance up to the promised level of 0.7 percentage of their GDP's (the level decreased instead: $0.22 \%$ by 1998 , EU average: 0.34\%, numbers include debt relief). The recent Barcelona Spring Council (2002) confirmed to reach the eventual target of 0.7 percent but for the immediate years to come, the EU average will not rise above 0.36 percent.

The North-South divide is thus reflected in the operationalisation of the Rio Commitments. The European Commission, however, gave a fair acknowledgement of this situation in its Communication to the Council and the Parliament "Ten years after Rio: preparing for the World Summit on Sustainable Development in 2002” .

The Communication reconfirms the relationship between development and environmental issues, acknowledges the lack of progress and calls for a "renewed political commitment to the revitalisation of Rio and to the implementation of Agenda 21. When it comes to the concept of sustainable development, the Commission sees 
Agenda 21 "As a long-term blue-print for sustainable development in the 21st century". In addition to the revitalisation of Rio, the Commission looks for a forward looking agenda against the background of overarching themes of poverty eradication and sustainable production and consumer patterns. The Ministerial declaration of the UN/ECE regional preparatory meeting held in Geneva (24/25 September 2001), which conclusions fed into the preparatory meetings of the CSD in 2002 for the WSSD, reflected by large, this forward looking agenda by putting forward the following points as priorities for the WSSD:

- Poverty eradication

- Sustainable management and conservation of natural resources

- Making globalisation work for sustainable development

- Improving governance at all levels

- Financing for sustainable development and

- Education, science and technology for decision making.

As regard the contribution coming from RTD or technology in general, no new conceptual thinking can be observed. Concerning capacity building and technology transfer, the Commission calls for a recommitment but now clearly makes a link to a financial back up of policy initiatives in this area. The June 2001 Environment Council picks the issue up as follows: "The private sector plays a key role and should be part of the efforts to achieve sustainable development", also through foreign direct investment. Commitments by the business community to corporate responsibility, environmental accountability and exchange of best practices and technology transfer could be parts of "a global pact", which would include public-private partnerships as well as an increased North-South co-operation". Furthermore, the June Council considers the enhancement of technology transfer and capacity building, among others as a way to strengthen the institutional framework for sustainable development.

It is therefore interesting to note that the Ministerial Declaration of UN/ECE preparatory meeting (EU 15, Norway, Switzerland, CEE, Russian Federation, US and Canada) addresses the issue of "science and technology for decision making" at some length, predominantly because of the input by the US side. The Ministerial Declaration calls, among others, for:

-enhancement of scientific knowledge and to improve the processes for generating, sharing and using science for sustainable development

-more action oriented interdisciplinary research with greater focus on prevention and early identification

-the incorporation of science and technology for decision making

-to expand scientific and technological co-operation to address new and emerging risks

-promote broader technology transfer and capacity building.

The US international agenda and the European seem to diverge. Whereas the Americans seem to put a lot of emphasis on "science and technology for decision making", here the EU lacks a clear stand. Conversely, after the Bush administration came in office, "sustainability" is not an objective in any official policy whereas the Europeans have made it key to their institutional activities, both at treaty level and in supplying national and EU strategies for sustainable development. An earlier, single 
Committee on Sustainable Development under the Clinton Administration has been abolished.

World Summit on Sustainable Development, Johannesburg 2002

The EU/US divergence became apparent at Johannesburg as expected. Also the G77 reluctance towards ambitious environmental targets continue to exist. It left the EU as the only block which operated on an agenda aiming at an action-orientated outcome with clear and measurable objectives. The Agenda of Johannesburg was finally reduced to 5 major areas: Health, Biodiversity, Agriculture, Water and Energy. In the final political declaration of Johannesburg the issue of the importance of Science and Technology did not appear, although its role in achieving particular goals should not be ignored. The expectations before Johannesburg were not high, but nonetheless, the following targets were concluded:

1. Halve by 2015 the proportion of people lacking access to basic sanitation complementing the Millennium Development Goal on access to clean water.

2. Commitment to minimise harmful effects on human health and the environment from the production and use of all chemicals by 2020 .

3. Commitment to halt the decline of fish stocks and restore them to sustainable levels no later than 2015.

4. Recommitment to national strategies on sustainable development by 2005 .

5. Commitment to halt the loss of bio-diversity by 2010, as earlier agreed by the parties to the Bio-diversity Convention.

On Energy, among others, an agreement to take joint actions to improve access of the poor to energy and an agreement to increase urgently and substantially the global share of renewable energy sources(both agreements without clear targets) were concluded. Concerning sustainable consumption and production an agreement on the EU proposal for a 10-year framework for programmes on sustainable consumption and production was also agreed. All Rio principles were reconfirmed as well as the agenda's agreed at Doha and Monterrey, the major two other global negotiation contexts in which the sustainability agenda will have to be moved forward.

\section{From the pursuit of happiness to the pursuit of sustainability}

This section deals with the problem of an contradiction between long-term planning and democratic decision-making. It is simply not plausible that a much needed longterm sustainable development policy can get off the ground, if for the achievement of consensus on such a policy, we are fully dependent on the usual arenas of societal conflict resolution, e. $g$ the arenas of the "market" and of "(Party) politics". In this paper I will first shortly outline the advantages and limits of those two conventional regulatory mechanisms. I will subsequently make the case for a third international arena of long-term planning which could overcome the above-mentioned contradiction. 
In the recent past, to cite an example, some European Member States could not achieve CO2 reduction targets, planned to be reached within a decade (from 1990 to 2000) because in-between party-political decisions or economic changes interfered with the conditions which should make those reduction targets possible, such as decisions on energy-duties, the level and scope of eco-taxes or simply an unpredicted levels of economic growth. The current economic growth which in the EU is not particularly at a high level, will nonetheless make it already difficult and contestable whether the targets under the Kyoto Protocol can actually be achieved in most of EU Member States. The temporary party-political decisions change on every occurrence and undercut (most often as unintended consequence) those necessary conditions, which have been democratic in nature, but raise the issue of the impossibility of setting fixed sustainability targets for the long-term. Conversely, the setting of such standards in the current party-political infrastructure of most modern democratic states raises the issue of a naturally unwanted elite or "eco-dictatorial" type of determining sustainability or environmental targets.

Since these contradictions already arise in the national context, it is clear that in the international context, the (necessary) negotiations on the long or medium term targets is even more difficult: negotiators often come back home with results which are difficult to defend in their own national political setting or need to be renegotiated when governments change. Given the timeframe, these negotiations demand, for example the Kyoto Protocol (nine years after the conclusion of the Convention on Climate Change) and the Biosafety Protocol (8 years after the conclusion of the Biodiversity Convention) this is not unlikely to happen. As the behaviour of the US under the Kyoto Protocol illustrates, this can even imply the complete withdrawal from commitments made earlier by former negotiators.

In addition, if consumption patterns and levels would need to be adjusted for the actual achievement of sustainability targets, our political regulatory capabilities are, in democratic, open market societies, naturally limited. The appropriate level of consumption in relation to sustainable development is in itself difficult to determine. High levels of consumption certainly contribute to more environmental stress, but too low levels of consumption adversely affect the economy thereby bringing a sustainable level of economic growth out of reach. The ideal ultimate goal of a decoupling of economic growth from environmental degradation seems incontestable: the difficult issue is how to get there and how realistic are current plans in relation to this goal.

Against this background, some authors have argued for the implementation of what could be called a third arena which could complement received powerful market and state regulatory mechanisms (see Keijzer et al, 2002, Susskind, 2000; Von Schomberg 1998, and Birkeland, 1996). Such an arena make it possible to reconcile democratic decision making with long-term planning without compromising market and state regulatory mechanisms in the areas in which they have shown to be, and will continue to be effective. Such an arena would, of course, need to be operational both at the national and the international level.

We will make the case here, that we are in need of institutional innovations which provides the infrastructure of a new arena for societal conflict resolution. Such an arena was not foreseen in the constitutional design of modern nation states when they 
came into existence at the edge of the $19^{\text {th }}$ century, at a time when the environmental resources were believed to be inexhaustible, a view which was not substantially challenged before the end of 1960's.

Table 1 represents three modes of societal conflict resolution which are mutually adjusted to each other and complement each other at the different dimensions at which they are operational. The three dimensions involved represent the potential conflict among individuals in satisfying their consumption needs and preferences, the possible conflictual relationship between individuals and the society in which they live, and thirdly the possible conflictual relationship between individuals, society and the environment (e.g. the limited availability of environmental resources across generations). Those dimensions relate to the interests at stake, at each of those levels: the preferences of people, their individual rights within their society and the basic needs of each individual for the long term and in a trans-generational and transsocietal sense. Those interests can be realised by the appropriate processes of trade, democratic vote and (international) public debate and negotiation and international standards of justice. These processes occur in the appropriate arenas for conflict resolution, e.g. the market, the sphere of politics and the arena for long-term planning and policy. These distinctions are analytical in nature and are made here in order to elaborate on some new mechanisms of societal conflict resolution; in actual situations those arenas may overlap.

We are very familiar with the first two dimensions. The range of preferences and wishes of individuals in the relation to the acquisition of a large number of goods can be effectively realised by market-regulation. A substantial number of rights of individuals can be granted or realised by the process of governmental/parliamentary law making processes. This can vary in accordance with the national context but all democratic states have particular individual rights which are not dependent on or subject to utilitarian considerations. With regard to achieving sustainability, these two dimensions are still forceful and relevant, but limited as will be demonstrated below.

\section{Principle advantages and limits of market-regulation}

Two principle advantages of market-regulation can be mentioned. First, all strategies concerning energy or eco-efficiency could be effectively realised through marketregulatory mechanism, since obviously such strategies will reduce the costs of the production of goods and thereby create market-advantages. The usual win-win scenarios reflect such an approach. The advantages of market-regulatory instruments will be even increased if product-prices would also reflect the cost of the exploitation of environmental resources, if governments would fully embark to facilitate the conditions for such markets on the basis of eco-taxes and similar instruments to incorporate the prices for the regeneration of environmental resources. The Factor 4 argument $^{1}$ (or some argue even for a factor 10) to double our wealth with half of today's actual usage of natural resources is by large based on "clever" market-based strategies and it is incontestable that much can be achieved by taking this route. The positive results from this strategy will become clear when the "externalities", e.g. the

\footnotetext{
${ }^{I}$ See Factor 4, C. von Weizaecker et al, 2000. The argument in this book goes, however, also beyond the usual market-based strategies and the authors also try to make plausible that our concept of "wealth" should not be associated with GDP figures in a one-sided way.
} 
external costs which include regeneration/repair costs of environmental resources will be included in the prices.

Secondly, the privatisation of goods has also shown to have positive environmental effects. Economists already postulated the "Tragedy of the Commons" in 1963, which states that "goods" which were not owned by anybody, such as parts of the oceans etc, became free places for dumping waste and were principally neglected. Privatisation or bringing such goods in territorial ownership, implies that those goods will be taken care of.

The above mentioned principal two advantages have been far from fully exploited (such as incorporating externalities in the prices of goods), but do have principle limits. Although none would sensibly argue against eco-efficiency strategies and having cars run on a fraction of the current fossil-demands, these advantages are immediately nullified if consumers decide to increase the number of cars per household and or increase their mobility because of the reduction of costs. The truth of the "tragedy of the commons" has also a systematic down-side: there is no principle limit to the ways private owners will decide to exploit their resources and there is no guarantee for the regeneration of those resources nor the maintenance of the public value of those goods. The necessity of the regeneration of particular resources, such as tropical rain woods etc in terms of sustainability are by now acknowledged but there is currently no mechanism available which would regulate a minimal amount of such resources to be available for the long-term. Innovative market-based mechanisms such as tradable emission or pollution rights do allow for setting over-all limits for exploitation or pollution. However, such mechanisms are of course not fully market-oriented since they presuppose "an instance" which could legitimately fix the standards for overall-exploitation. This is precisely the new element we need to agree upon: "who can legitimately decide upon what basis". Until now, the Kyoto Protocol mechanisms provide the only example for worldwide possible solutions for one particular environmental issue. Equally the coverage of particular basic needs, such as the provision of clean drinking water, could be under threat if the access and supply of such needs would be fully outside of any regulatory control.

\section{Principle advantages and limits to national governmental regulatory capacities}

The second dimension of societal conflict resolutions concerns mechanisms for the distribution of goods in a socially justifiable way. The fulfilment of basic needs can be guaranteed, either by subsidies for the production of such goods at low-market prices as for instance the production of agricultural produce in the immediate post-war period in Europe illustrates or by (semi-) government controlled supply. Governments can also define the conditions under which markets operate and regulate by productauthorisation procedures entailing environmental impact assessments, cost-benefit analysis etc. In addition, governments regulate and shape the basic rights that individuals in their society have. These regulatory means show now also their limits and in some cases such as the subsidies on the agricultural produce have shown to be counterproductive, although the regulatory means as such will continue to be highly valuable. 
The basic right of individuals to acquire property and/or natural resources is increasingly a theoretical right, seen from the perspective of an individual who is recently born. For example, the global energy resources or the access to those resources, are by large in private hands. A substantial number of governments have even actively contributed to the acceleration of this process since the 1980 s by selling natural resources, for prices which are often below the regeneration costs of those resources while it is far from guaranteed that there is in fact a given possibility of the regeneration of those resources. The basic right of individuals to acquire property came into existence against the background of the consideration that a "pursuit of happiness" and indirectly the prosperity of the society as a whole could be shaped in the awareness of the unlimited availability of natural resources (this was particularly the case for the emigration countries in the Americas and Australia). Those resources could be traded as "free goods" so that every individual, but also future generations could profit from the availability and/or access and exploitation of those goods. However, more than 200 years later, everything which could possibly be privately owned is already for a large extent in private hands and the environmental resources show now their limited availability and potential for regeneration in a particular timehorizon. The pursuit of happiness has turned into a "first come, first serve" system, leaving future generations in a basically unequal starting position, thus undermining the original notion of social justice associated with this on the individual focused 'pursuit of happiness' strategy.

In addition, the appeal to property rights has led to a situation which runs counter to the original idea which lay behind these rights when they were established. This appears now more recently also to become true for rights such as the right to exploit technical innovations covered by intellectual property rights. The establishment of a system of intellectual property rights has certainly contributed to economic growth and prosperity but the societal capacity to shape and control those technologies in the range of their applications and consequences (intended and unintended) have become increasingly difficult and the ongoing process of democratisation since the enlightenment has therefore become limited in its scope. Democratic decision making with regard to technological developments is difficult to implement. In the field of some "high tech" areas, it is increasingly more difficult to exploit new inventions without being faced with the problem to link those with existing patents for which an inventor would need to buy his way in. The implication is that innovations can only arise in the context of companies and research groups who bring with them the necessary financial means. In the area of high-tech, the individual "inventor" nowadays hardly still exists.

Another problematic feature of the current situation in western democracies is that national governments (and their taxpayers) are forced to a policy of compensation, since they carry the enormous environmental costs for the unforeseen or unintended negative consequences (or risks) of technological developments: the problems concerning the safe and ultimate disposal of nuclear waste provides a welldocumented example. ${ }^{2}$

\footnotetext{
${ }^{2}$ During the initial decades of the application of nuclear energy, the scientific consensus was that this problem would be resolved "meanwhile" further developing, applying and expanding the technology. This consensus did not break down earlier than the mid-seventies and optimal solutions are still outstanding today. The example of nuclear energy shows also the difficulties of "steering" technological directions. Opponents of nuclear technologies seem to have channelled their actions fully
} 
More fundamentally, however, is that our societal decision making mechanisms are exclusively aimed at the equitable distribution of goods whereas there is no mechanism that is aimed at the equitable conservation or maintenance of goods in such a way that in the future an equitable distribution (at world-wide level) is still imaginable. This is however precisely the type of mechanism which is needed if we want to meet the Brundlandt definition of sustainable development: we should not 'compromise the ability of future generations to meet their own needs'. The Brundlandt report did not fully clarify the concept of needs. However, given the complexity of the issue, one could argue that those needs would at least entail the basic needs related to the immediate conditions of survival of those generations, e.g. arable land for the cultivation of food crops, the availability of drinking water resources etc. Such an approach would be less ambitious than the approach of the Brundlandt report where the open definition of needs can still be rightly or wrongly associated with the objective of sustaining particular achieved levels of economic wealth. Nonetheless, the task ahead of us would remain enormous. To get a picture of this task, Wackernagel et al (1996) have developed the concept of the ecological footprint.

\section{Ecological Footprint}

The Ecological Footprint measures the amount of nature's resources of an individual, a community, or a country consumes in a given year. It is based on official statistics on consumption and this is translated into the amount of biologically productive land and water area required to produce the resources consumed and to assimilate the wastes generated using prevailing technology. Because people use resources from all over the world, and affect faraway places with their pollution, the Footprint is the sum of these areas wherever they are on the planet. The table with the most recent 1998 figures below shows that most of the western countries have a footprint that is a multiple factor of the available bio capacity in the country itself. Some of the constituting elements of the footprint can show dramatic figures. For example, the Netherlands uses 15 million hectares of agricultural land in other countries (whereas 2 million hectares is used within the NL) for example in countries such as India where Tapioca is grown as a crop needed to feed a population of 12 million pigs in the country. The differences among western countries can still be significant. The average American uses 24 acres to support his or her current lifestyle whereas the average Italian does with 9 acres.

One can tentatively draw from those facts that the fulfilment of basic needs is under threat as a consequence of high footprints, predominantly in the western world, and without any mechanism at hand which could regulate the use of the world-bio capacity in an equitable way. Demanding for such a mechanism for long term planning sounds utopian, since it presupposes among others, loss of sovereignty of nations over their national resources such as tropical forests etc. Today's international

\footnotetext{
on exploiting the possibility on rendering nuclear technology economically unfeasible by contributing to the very high transport and interim storage costs. (For instance, the transport/storage costs in Ahaus \& Gorleben (Germany) of nuclear waste in 1998 (surrounded by demonstrations) were estimated to have been over 100 million German DM (around 50 million Euro).
} 
political reality is that such issues are even far from being tentatively proposed at the international negotiation table.

The political more convenient assumption is that technological progress, from which the benefits on the long-term would be sufficiently shared among all nations to sustain a population growth rate that is not higher than what is needed for the coverage of all basic needs. However, without such a mechanism and accepting today's political reality, it implies that it is also utopian to believe we would achieve sustainability in terms of guaranteeing the fulfilment of basic needs of the world populations for the longer term. The mechanisms for guaranteeing social justice at national level do not have their equivalent at world scale. 


\section{An arena for long-term planning at the international level}

Yet, such an arena of long-term planning at the international level is slowly emerging and is inherently connected with some basic ethical and factual assumptions which drives us to negotiate at the international level to push forward the sustainability agenda: we are collectively confronted with the problem of making the world sustainable but find ourselves in unequal power situations as well as a lack of shared values, given the variations in socio-cultural values. The only way to move forward in such a situation as difficult as it is, is through continuous international public debate and negotiations during which those values and relative responsibilities need to be sorted out and reflected in international agreements. Our actual future oriented drive of societies is factually established at the national level and any call for a new future oriented ethics seems too superfluous. The problem is more to connect the in-built future orientations of particular societies with each other in a meaningful way since:

1. In modern society, our basic institutions have a de facto in-built future perspective in order to operate meaningfully, e.g. the institutions of the legal system and scientific system for instance, can hardly be imaginable in a meaningful way without any future perspective.

2. The constitution of many western societies already contains the rights for a "liveable environment". The actual problem is not the establishment and the recognition of the right as such, but its meaningful implementation in practice, thereby allowing for the necessary flexibility of what people consider "liveable" under particular circumstances and in the context of ongoing conflicting values and interests between different groups in society.

3. The objective of Sustainable Development, which is nowadays recognised in the EU treaty, UN Organisations and under the WTO entails also a future perspective. The problem is again, not the establishment of such a future perspective in the light of ongoing environmental degradation (this was mainly achieved in the 1980's) but how to cope with competing different future scenarios, developed by different societies at world scale and the actual problem to make "our future" scenario of trying to maintain a particular level of wealth, compatible with the development scenarios of the countries in the southern region. In discussing "future ethics" one cannot always surprises the feeling that what is actual meant is "our future", e.g. the future of one particular political community.

4. Economic assessments on the basis of our (e.g. some western societies) actual "ecological footprint" suggest that we already are in a situation that our claims on natural resources vis a vis the potential claim of others are not compatible with the rights and moral obligations we have already embraced and which we are ready to secure for our future generations. In other words, we can not morally and ethically prejudice and project a "future ethics" in a context where actual "futures" of others are being violated. 


\section{Conclusions}

In conclusion, we argue that the ambition level of Brundtlands definition is too high, if this is associated with sustaining wealth-levels which would claim disproportionate amounts of the world's available biocapacity. It should be downgraded to the level of securing the possibility to fulfil basic human needs, both for present and for future generations. "The future" is thus not an object of special ethical attention and it is through the operation of our societies inevitably linked with our present situation of how we deal with "others". Our ethical situation is that of a group of mountain climbers connected with each other by a rope: we are all responsible for each other (reciprocity argument) and the one who takes the lead needs to take care for those who follow (care argument). Given the fact of pluriformity (and most often, the nonuniversalisability) of values and norms, the reciprocity argument can only be meaningfully implemented by the institutionalisation of ongoing deliberations between different interest groups and indeed the establishment of mechanisms and deliberative procedures in order to allow for the adjustment of conflicting interests. Deliberative procedures both at national and at international level allow for precisely the needed connection and mediation of national societies in-builds future orientations. These procedures would not express a new type of ethics but rather makes it possible to act in a co-responsible way on the basis of an ethics we have already accepted. It just makes the structural move, to complement an individual focused and market-based pursuit of happiness at the level of a collective pursuit of sustainability.

Nonetheless, even with this down graded ambition level with regards to the definition of sustainability, the world's and nation's socio-political infrastructure needs to be renewed. The conclusion cannot be otherwise than that at even having exploited the full possibilities of market and governmental regulation (and we clearly have not done so), the target of sustainability in terms of securing the basic needs of future generations will not be within reach. A third arena underlying a truly international ethics of co-responsibility (e.g. the replacement for equity standards at national level) based on new deliberative procedures would thereby combine the objectives of democratic legitimacy and need long-term target setting. Here it is now appropriate to give some indications for the three general features and requirements for the implementation of such deliberative procedures in which such an ethic would express itself naturally and make long-term planning possible. The following six Elements are crucial for such a new third emerging arena:

1. Public debate: To be co-responsible includes being personally responsive. It is clear that the norms of specific technical professions are insufficient because they arise from restricted perspectives. A true ethics of co-responsibility must be both interdisciplinary and even inter-cultural, in order to provide a standard of justice for evaluating and balancing conflicting occupational role responsibilities. If we fail to provide such an ethic, we inevitably continue to aggravate the clash of cultures and unarticulated hostile responses to particular (globalised) technologies.

An ethics of collective co-responsibility is expressed at the level of free (international) public debate in which all should participate (or at least all responsible governments). It is unethical and even unreasonable to make any one individual responsible for the consequences and/or (adverse) side effects of our collective (especially technological) 
actions. It is, however, ethical and reasonable to require individual participation in public debates (subject, of course, to the particular situation) and for governments to negotiate actively at the international level, or at least make this the default position for which persons/states must give reasons for being excused from such a duty. Upon everyone's shoulders rests a particular ethical-moral obligation to engage in the collective debate that shapes the context for collective decision-making. Clearly the withdrawal of the US from the Kyoto Protocol was accompanied with a widely shared ethically motivated disapproval of US behaviour which only concerned the unilateral withdrawal, not their views on climate change as such.

If we trace, for instance, the history of environmental challenges, we see that many issues which depend on the involvement of personally responsible professionals were first identified and articulated within the public sphere. Public deliberation does not primarily aim at creating by itself a reasonable consensus, but serves, among others, the function of presenting different relevant issues to the more or less autonomous systems and subsystems of society -- that is, to politics, law, science, etc. The typically independent discourses of politics, law, science, etc. are called upon to respond to issues raised in public debate. An appropriate response by the appropriate subsystem to publicly identified and articulated issues constitutes a successful socioethical response. Conversely, responsible representatives of the subsystems are drivers for new debates, when they publicise particular aspects of an issue that cannot be fruitfully resolved within the limits of some specialised discourse. The continuous interaction between the autonomous subsystem discourses and a critically aware public provides a corrective for entrenched societal contradictions between opposing interests, stakeholders, or cultural prejudices.

2. Technology assessment: To be collectively co-responsible involves developing transpersonal assessment mechanisms. Although the institution of the public realm and interactions with the professionalised subsystems makes it possible for individuals to be co-responsive, these deliberations are in many cases insufficiently specific for resolving the challenges with which technological development confront us -- that is, they do not always lead to the implementation of sufficiently robust national or international policies. Therefore all kinds of specific deliberative procedures -- for instance deliberative technology assessment procedures -- must be established to complement general public debate and to provide an interface between a particular subsystem and the political decision-making process. The widely discussed consensus-conferences are one example of an interface between science and politics and are currently advocated among others in the context of the ScienceSociety Action plan of the European Commission.

The implementation of ethics codes by corporations also constitutes an interface between the economic sector, science, and stakeholder interest groups, while national ethics committees are often meant as intermediaries between the legal and political system. Some members of the European Parliament have called for "consumer councils" based at major businesses. Experiments with such boundary activities or associations have been, depending on the case, more or less successful. They represent, however, important experiments for enabling citizens to act as coresponsible agents in the context of technological decision-making. Yet the absence of adequately deliberative forums is certainly one reason why we are not yet able to democratically plan our technological developments. 
3. Constitutional change: Collective co-responsibility may eventually entail constitutional or structural political change. The initiation of specifically new forms of public debate and the development of transpersonal science and technology assessment processes may eventually require constitutional adjustment. Indeed, the adaptation of specific deliberative principles in our constitutions must not be ruled out. Consider, for instance, the possible implementation of the precautionary principle, which is inscribed in the European Treaty and now also guides important international environmental deliberations (the Kyoto Protocol on Climate Change, the Bio safety Protocol, etc.). This principle lowers the threshold at which governments may take action to restrict scientific or technological innovation. According to the precautionary principle, one should err on the side of precaution. It does not have to be shown with certainty that bad consequences will follow; it is sufficient if there is an absence of scientific certainty in cases where there is some indication of possible serious or irreversible harm to human health or the environment. The very implementation of such a principle requires new and badly needed intermediate deliberative science-policy structures. It imposes an obligation to continue to seek scientific evidence and enables also an ongoing interaction with the public on the acceptability of the plausible adverse effects on the chosen level of protection. The principle also requires companies to become more proactive and necessarily shapes their technoscientific research programs in specific ways. The Precautionary Principle represents an important example of a norm for global governance.

4. Science for Sustainability: Jerry Ravetz (2002) has made the case for a new type of approach to the science-policy interface. Policy-makers can not rely anymore on the truth-producing system of science whenever we need to interfere with complex systems, both ecological as societal, and is surrounded by scientific uncertainties, controversies if not plain scientific ignorance. Policy makers need therefore new tools in which they can assess the quality of the information rather than the truth of individual scientific statements. Governance, precautionary principle, and sustainability should be inherently connected to each other to ensure a high-quality policy process. Such an integrated approach towards governance, precautionary principle and sustainability define the margins within which society progressively develops and also allows for testing and elimination of unsustainable options. The recognition and selection of sustainable options can be achieved by adoption of best practices and the use of best available technologies. In order to provide scientific support for policy making the interface of science/policy needs thus to be conceptually revised. The necessary "science for sustainability" can be provided through an interface of a quality assessment of scientific information, which would guide the selection and use of scientific information.

\section{Normative (deliberative) design based on foresight/back casting}

Major sustainability issues remain controversial and go back and forth between the scientific level and policy-level where there is no agreement on the normative reference points to be used as a point of departure. The Kyoto Protocol is by large negotiated on the basis of what national governments seem to believe to be politically feasible rather than on the type of environmental changes we would deem to find acceptable. The setting of a normative target, let's say 1 degree temperature rise at the global level is of course contestable, since we cannot yet foresee what the consequences of that target would be. However, deliberative procedures such as the 
application of the precautionary principle helps us to find consensus on such targets. An extra-parliamentarian committee in Netherlands has tried to elaborate such a strategy, beyond the immediate constraints of Party-Politics, for Climate Change policy in 1996, based on hearings of experts from different backgrounds. Back casting from such a temperature rise of 1 degree Celsius in twenty years time, gave outcomes on actual needed CO2 reduction of up to 60 percent of the 1990 level. Such a reduction is not political feasible, yet we must then admit that possible temperature rises may be higher. Without setting any normative target, the issue will remain controversial and frustrate a co-ordinated way to move forward. Foresight studies that monitor changes would be needed to re-orientate policies, once those normative target could be clearly defined.

6. System innovation offers a route for achieving sustainability benefits. This requires the management of processes of evolution and orientation of private and public actors to transition goals. Ideas about how to manage transition processes are worked out into a model for governance, called transition management (Kemp et al. 2001). Transition management tries to orient existing dynamics towards transition goals chosen by society. Through its focus on long term goals of sustainability and its attention to dynamics it aims to overcome the conflict between long-term ambition and short-term concerns. Key elements are the formulation of a transition goal and the use of process management based on a philosophy of learning- by-doing and doingby-learning. Actual policies and goals are evaluated in development rounds. Dutch environmental policy makers have adopted the model of transition management, developed by Kemp et al.(2001) (see also Blueprint project, financed under the FP5 STRATA programme), as a model for working towards a transition in energy, agriculture and transport.

This model moves away from the conventional technology focussed innovations whereby governments still can set normative targets, but leave it up to the actors within a system to collectively work out the methods on how to get there. Variation in the application of technologies and niche management of particular technologies in the mid-term would allow convergence to more structural changes in the long-term. The Strata Blueprint project shows that it is not meaningful for instance to define, or even think it would be possible to define particular "environmental" or clean technologies, since innovations in the system can come from all available technologies. Clearly, system Innovation has an undeniable international dimension.

Arie Rip (2002) has made the case for conceptualising the interaction of technological and societal developments in terms of co-evolution of societal and technological systems. Although this multiactor-based process always takes place, it is not necessary reflexive in nature. Recognising the "Collingridge Dilemma" which implies that at an early stage of technology development, the nature of the technology (and the articulation of interests) are still malleable - but it is unclear what the effects and impacts will be. By the time these become clear, the technology is entrenched and vested interests make it difficult to change the technology. In order to make actors aware of their mutual shaping of technological developments this process of coevolution can be made "reflexive". From the point of a reflexive process of coevolution a real, although limited space for governance and "steering" of technological innovations/developments can arise. Equally Sustainable Development can not be pinned down in concrete terms, but is conceived as a process whereby 
policies and societal actors set the conditions for its direction without a predetermined end-point. This theoretical understanding aligns with practical policies which aim at System innovation rather than on particular technologies that could foster sustainable development

\section{Visionary Enterprises}

Long-term planning must also become more visible at the core business of Enterprises. Collins and Porras (1996) have done much cited research on the longterm plans of enterprises. They have categorised enterprises as "visionary" when they are led by a particular lead-ideology. They argue: The organisation's fundamental reason for existence beyond just making money- a perceptual guiding star at the horizon, not to be confused with specific goals or business strategies". These authors have not applied the case of the visionary enterprise to sustainability issues, but obviously there is a natural overlap. Such companies need to adapt themselves to changing conditions without losing their identity. An example of a company which has clearly gone beyond just conforming to national regulations is the UK-NL based multinational Unilever. In 1996 the World Wildlife Fund (WWF) and Unilever have joined forces and collectively constructed a long-term programme for sustainable fishery. They have founded an independent non-profit organisation to foster worldwide fishery. At the same time they apply "standards of Sustainable Fishing" which is also monitored by independent certifying agencies to control those standards. Unilever has set the goal to fully comply with those standards by 2005 . The example shows that also Multinationals cannot anymore to refuse collaboration with other actors in society or even need to become pro-active and help to bring about new agencies. Obviously without fish in the oceans there will no fishing industry.

Innovation is driven by certain cultures within (business) organisations. Environmental or Sustainability performance has become a key factor in the public's judgement of Enterprises and this is reflected in a growing number of annual reports of companies concerning this matter. There is a strong support for the link between superior environmental characteristics in product portfolios and the general ability to innovate (see the 2001 Report "Buried Treasure" of the United Nations Environment Program). The engagement of non-business partners gives enterprises a better understanding of customer concerns. Public-Private Partnerships could include research-businesses or public research institutions to facilitate cost-effective innovation. RTD policies need to be aligned with environmental and enterprise policies in order to achieve coherence and allow public-private partnerships to arise.

The consultant company "SustainAbility" has worked out for the UNEP Programme a Corporate Sustainability Performance matrix against which Business Success can be measured in terms of financial drivers and financial performance. The argument becomes here thus even stronger: Businesses which include governance, environmental, socio-economic (including human rights) factors as well as engage with other business and non-business partners, will gain financial benefits on the long-term although they are not exclusively linked to these financial benefits, since the prevailing motive of a visionary enterprise would be: to sustain on the long term. 


\section{Key Research Areas to meet Sustainability Demands in relation to our conclusions.}

This paper argues that sustainability should be approached from the angle that future generations should be prevented from meeting basic needs. We have acknowledged that these basic needs are already being violated by current unsustainable trends, thereby comprising basic human needs of current generations. The following research need, which was acknowledged under FP5 INCO programme, remains therefore important in the EU international research co-operation projects and has a potential under the European Research Area:

\section{Research which supports policies which enable the provision of basic human needs, such as water, food, sanitation and health.}

The paper argues that the regulatory capacity of the "market" and "politics" have reached their limits. However, it is acknowledged that those conventional regulatory mechanisms have not yet been fully exploited. In addition, guiding socio-economic research seems necessary to explore the possibility of new inventive regulatory mechanisms such as tradable emission and pollution rights. The whole spectrum of research related to "Eco-efficiency" topics remain therefore also highly relevant (since we are still far away from the Factor 4 objective). Here guiding socio-economic research is needed under which market incentives or policy conditions, Eco-efficiency targets can most likely be met.

\section{Research which increases Eco-efficiency which includes the use of renewable resources. Guiding Socio-economic Research: regulatory mechanisms and market incentives and policy conditions.}

We have argued that above research has its limits, since there is no (international) regulatory means which allow for the setting overall-maximum resources consumption or environmental pollution. All "decoupling" issues, such as decoupling energy consumption from economic growth or decoupling transport growth from economic growth and /or energy use will only be possible if new regulatory mechanisms which make long-term planning possible will become available. We have acknowledged that the political climate is not yet ready for having such mechanisms available. However, any prospective mechanism needs to be based on Research facts concerning the world's available bio-capacity. Thus ongoing research is needed concerning our "Footprint". It has to be noted that this "footprint" changes whenever our technological capacity increases.

\section{Research mapping our Footprint on national, regional and global scale (under priority 6 and 7 of FP6)}

The following research topics follow the 6 major elements relating to our "third arena" argument:

4. Research is need how Public debate can be filtered in the policy process and how new deliberative mechanisms can be introduced in conjunction with new international institutions such as the WTO. The Science and Society Action, which 
wants to promote deliberative mechanisms in context of the use of scientific knowledge can be interpreted to be a step in that direction.

\section{Technology Assessment and Technology Foresight}

Sustainability targets will be by large dependent on our technological capacity and the speed in which we are able to have innovative technologies accepted in society. The science-policy and science-society interface needs deliberative mechanisms. Research is need to assess technologies in terms of possible future acceptance and sustainability demands

\section{Constitutional Change: Applying the Precautionary Principle}

The Precautionary Principle is an early example of a policy principle which can provide a norm for global governance. It is part of the EU treaty. The Principle is conceptually matured at the policy level of the EU. However, its application needs ongoing specification and adaptation in time and to specific area's: chemical substances, endocrine disrupters etc. Research is needed how the principle can be materialised for those areas.

\section{Normative design based on foresight and back casting}

The meaning of this issue has been elaborated above. Back casting from normatively (be it experimentally) predefined targets of acceptable levels of pollution and consumption of natural resources is necessary in order to be able to monitor and reorientate current policies in relation to their goals.

\section{System innovation}

In order to identify the necessary policies for System Innovation is it important to identify key technologies and the necessary variation between them. Socio-economic research is needed to identify key actors and their collective behaviour towards innovation. 
Dimensions of societal conflict resolution

\begin{tabular}{||l|l|l|l|l||}
\hline \hline Dimensions & Interests & Standards & Processes & Arena \\
\hline \hline $\begin{array}{l}\text { Individuals/ } \\
\text { Society }\end{array}$ & $\begin{array}{l}\text { Wants/ } \\
\text { Preferences }\end{array}$ & Efficiency & Trade & Market \\
\hline $\begin{array}{l}\text { Individuals/ } \\
\text { Society/ } \\
\text { Environment }\end{array}$ & $\begin{array}{l}\text { Reeds/ } \\
\text { Responsibilities }\end{array}$ & $\begin{array}{l}\text { Ethics of Responsibility- } \\
\text { Precautionary Principle/ } \\
\text { Pursuit of sustainability }\end{array}$ & $\begin{array}{l}\text { Debate/ } \\
\text { Mediate/transition } \\
\text { management } \\
\text { Negotiate }\end{array}$ & $\begin{array}{l}\text { Politics/stakeholder } \\
\text { agreements }\end{array}$ \\
$\begin{array}{l}\text { Pong term } \\
\text { sustainable } \\
\text { development/International } \\
\text { negotiations }\end{array}$ \\
\hline
\end{tabular}

Source: Modified and adapted from: Birkeland (1996), further elaborated by Von Schomberg (1998) and Keijzers et al (2002) 


\section{SUSTAINABILITY PROGRAM \\ ECOLOGICAL FOOTPRINT ACCOUNTS}

Projects and Results

1998 National Account Results (latest available accounts)

\begin{tabular}{|c|c|c|c|c|c|c|}
\hline Country & \begin{tabular}{|l} 
Total \\
Footprint
\end{tabular} & $\begin{array}{l}\text { Biocap } \\
\text { acity }\end{array}$ & $\begin{array}{l}\text { Ecological } \\
\text { Deficit }\end{array}$ & $\begin{array}{l}\text { Total } \\
\text { Footprint }\end{array}$ & $\begin{array}{l}\text { Biocap } \\
\text { acity }\end{array}$ & $\begin{array}{l}\text { Ecological } \\
\text { Deficit }\end{array}$ \\
\hline & \multicolumn{3}{|c|}{ Global hectares per capita } & \multicolumn{3}{|c|}{ Global acres per capita } \\
\hline & & & & & & \\
\hline & & & & & & \\
\hline & & & & & & \\
\hline & & & & & & \\
\hline World & 2.4 & 1.9 & -0.4 & 5.8 & 4.8 & -1.1 \\
\hline & & & & & & \\
\hline & & & & & & \\
\hline & & & & & & \\
\hline & & & & & & \\
\hline Argentina & 3.2 & 6.3 & 3.2 & 8 & 16 & 8 \\
\hline Australia & 7.8 & 16 & 8.0 & 19 & 39 & 20 \\
\hline Austria & 4.9 & 2.8 & -2.2 & 12 & 7 & -5 \\
\hline Bangladesh & 0.5 & 0.3 & -0.3 & 1.3 & 0.7 & -0.6 \\
\hline $\begin{array}{l}\text { Belgium \& } \\
\text { Luxembourg }\end{array}$ & 6.3 & 1.2 & -5.1 & 16 & 3 & -13 \\
\hline Brazil & 2.3 & 6.0 & 3.7 & 6 & 15 & 9 \\
\hline Canada & 7.8 & 14 & 6.2 & 19 & 35 & 15 \\
\hline Chile & 3.5 & 4.6 & 1.1 & 9 & 11 & 3 \\
\hline China & 1.6 & 1.0 & -0.5 & 4 & 3 & $\begin{array}{l}-1 \\
\end{array}$ \\
\hline Colombia & 1.6 & 2.6 & 1.0 & 4 & 6 & 2 \\
\hline Costa Rica & 2.2 & 2.4 & 0.2 & 5 & 6 & 1 \\
\hline Czech Republic & 5.0 & 2.3 & -2.7 & 12 & 6 & $\begin{array}{l}-7 \\
\end{array}$ \\
\hline Denmark & 6.6 & 3.4 & -3.2 & 16 & 8 & -8 \\
\hline Egypt & 1.6 & 0.8 & -0.8 & 4 & 2 & -2 \\
\hline Ethiopia & 0.8 & 0.5 & -0.3 & 2.0 & 1.2 & $\begin{array}{l}-0.8 \\
\end{array}$ \\
\hline Finland & 8.4 & 8.6 & 0.2 & 21 & 21 & 1 \\
\hline France & 5.1 & 3.0 & -2.1 & 13 & 7 & -5 \\
\hline Germany & 5.2 & 1.8 & -3.4 & 13 & 4 & -9 \\
\hline Greece & 5.2 & 2.3 & -2.9 & 13 & 6 & -7 \\
\hline Hungary & 3.3 & 1.9 & -1.4 & 8 & 5 & $\begin{array}{l}-4 \\
\end{array}$ \\
\hline India & 0.8 & 0.7 & -0.1 & 2.0 & 1.7 & $\begin{array}{l}-0.4 \\
\end{array}$ \\
\hline Indonesia & 1.1 & 1.8 & 0.8 & 3 & 5 & 2 \\
\hline Ireland & 6.1 & 6.3 & 0.2 & 15 & 16 & 1 \\
\hline Israel & 5.5 & 0.5 & -5.0 & 14 & 1 & 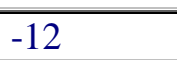 \\
\hline Italy & 4.1 & 1.1 & -3.0 & 10 & 3 & -7 \\
\hline Japan & 4.3 & 0.7 & -3.6 & 11 & 2 & $\begin{array}{c}-9 \\
\end{array}$ \\
\hline Jordan & 2.0 & 0.3 & -1.7 & 5 & 1 & $\begin{array}{l}-4 \\
\end{array}$ \\
\hline Korea Republic & 3.0 & 0.7 & -2.3 & 8 & 2 & $\begin{array}{c}-6 \\
-6\end{array}$ \\
\hline Malaysia & 3.5 & 3.5 & 0 & 9 & 9 & $\overline{0}$ \\
\hline Mexico & 2.7 & 1.7 & -1.0 & 7 & 4 & -2 \\
\hline
\end{tabular}




\begin{tabular}{|c|c|c|c|c|c|c|}
\hline Netherlands & 5.3 & 0.8 & -4.6 & 13 & 2 & -11 \\
\hline New Zealand & 8.8 & 24 & 15 & 22 & 59 & 38 \\
\hline Nigeria & 1.5 & 0.9 & -0.6 & 3.7 & 2.2 & -1.5 \\
\hline Norway & 8.0 & 5.9 & -2.1 & 20 & 15 & -5 \\
\hline Pakistan & 0.7 & 0.4 & -0.3 & 2 & 1 & -1 \\
\hline Peru & 1.4 & 5.4 & 4.0 & 3 & 13 & 10 \\
\hline Philippines & 1.3 & 0.6 & -0.8 & 3.3 & 1.4 & -1.9 \\
\hline Poland & 3.6 & 1.7 & -1.9 & 9 & 4 & -5 \\
\hline Portugal & 4.6 & 1.5 & -3.1 & 11 & 4 & -8 \\
\hline Russia & 4.3 & 4.8 & 0.5 & 11 & 12 & 1 \\
\hline South Africa & 3.8 & 2.6 & -1.1 & 9 & 7 & -3 \\
\hline Spain & 4.9 & 2.0 & -2.8 & 12 & 5 & -7 \\
\hline Sweden & 6.5 & 7.4 & 0.9 & 16 & 18 & 2 \\
\hline Switzerland & 4.4 & 2.0 & -2.3 & 11 & 5 & -6 \\
\hline Thailand & 2.0 & 1.4 & -0.6 & 5 & 3 & -1 \\
\hline Turkey & 2.2 & 1.4 & -0.9 & 6 & 3 & -2 \\
\hline United Kingdom & 5.5 & 1.7 & -3.7 & 13 & 4 & -9 \\
\hline $\begin{array}{l}\text { United States of } \\
\text { America }\end{array}$ & 9.8 & 5.4 & -4.4 & 24 & 13 & -11 \\
\hline
\end{tabular}

Source: Homepage of "Redefining Progress":

http://www.rprogress.org/programs/sustainability/ef/projects/1998_results.html 


\section{REFERENCES}

Agenda 21 and the UNCED Proceedings (1992). vol 1, Ed by N. Robinson, New York, NY.

Birkeland, J. (1996). Ecological Government, in Technology and Society Magazine nr 2, p. $21-28$

Collins, J.C and Porras, J (1996). Built to Last: Successful habits of visionary companies, London: Century Business

European Commission (2001). Communication from the Commission. A sustainable Europe for a better world. A European Union Strategy for Sustainable Development

European Commission (2001). Communication from the Commission to the Council and European Parliament. Ten Years after Rio: Preparing for the World summit on Sustainable Development in 2002

European Commission (2002). Communication on the External Dimension of Sustainable Development.

European Commission (2002). Report from the Commission (March 2002). Environmental Technologies for Sustainable Development

European Union (2002). Spring Barcelona Council Conclusions

Keijzers, G and Jeurissen, R (2002). Duurzaam Ondernemen, Toekomstethiek in Dialoog, Deventer: Kluwer

Kemp, R and Rotmans, J (2001). The Management of the Co-evolution of Technical, Environmental and Social Systems, paper presented at the international conference: Towards Environmental Innovation Systems, Garmisch-Partenkirchen 27-29 September 2001.

Marine Stewardship Council. Website: http://www.msc.com

Ministrial Declaration of the United Nations ECE Regional Preparoty Meeting for the World Summit on Sustainable Development, December 2001

Redefining Progress. Homepage:

http://www.rprogress.org/programs/sustainability/ef/projects/1998_results.html

Suskind, L (1999). Super Optimization: A new approach to national environmental policymaking, Paper presented at a Seminar organised by the Dutch Ministry of the Environment, January 1999

United Nations Development Programme (1999). Human Development Report

United Nations Environment Programme and SustainAbility (2001), Buried Treasure, Uncovering the business case for corporate sustainability

Ravetz, J.(2002), Science for Sustainability, in: Proceedings of the STRATA consilidating workshop: Science and Technology Policies in Europe: new challenges, new responses, Brussels, 22-23 April 2002, published by the European Commission (forthcoming) 
Rip. A. (2002), Challenges for Technology Foresight and Assessment and Governance, in: Final reports of the STRATA consilidating workshop: Science and Technology Policies in Europe: new challenges, new responses, Brussels, 22-23 April 2002, published by the European Commission (forthcoming)

Von Schomberg(1998), Omstreden Biotechnologische Innovatie. Van publiek domein naar lange termijn planning, Preadvies Nederlandse Vereniging voor Bioethiek. Utrecht: Nederlandse Vereniging voor Bioethiek

Wackernagel, M and Rees, R. E. (1996), Our Ecological Footprint. Reducing Human Impact on Earth, Gabriola Island: New Society Publishers

Weizaecker, E et al (2000), Factor 4, Frankfurt: Fisher Verlag

World Watch Institute (2002), State of the World 2002, New York, W.W. Norton and Company. 